\title{
Gustave Doré Y El Libro De Ruth De Gilberto Owen: Una Interpretación Visual
}

\author{
Dr. Alfredo Zárate Flores \\ Full-time Professor \\ Art and Business Department \\ Engineering Division \\ Campus Irapuato-Salamanca \\ University of Guanajuato \\ Jaime Obed Cervantes Pérez \\ Former Student \\ Degree in Digital Arts of the Art Department and company \\ Engineering Division \\ Irapuato-Salamanca Campus \\ University of Guanajuato
}

\begin{abstract}
The present article tries to develop a link between the poetic expression of the mexican writer Gilberto Owen and the plastic expression of the french illustrator GustaveDoré. We are interested in developing a visual interpretation of Owen's poems The Book of Ruth. This work explores some categories of the illustration of Doré to develop, from the use of foreshortening, the sequence of plans and the illumination five illustrations whose intention is to make manifest the relationship between literature and the visual arts from a perspective related to eroticism from the George Bataille'sperpective.
\end{abstract}

Keywords: Illustration; Gilberto Owen, GustaveDoré; Foreshortening; Sequence of plans; Lighting; Eroticism.

La relación entre la literatura y las artes visuales es intensa y altamente productiva. En tanto expresiones representativas o miméticas, la literatura, la pintura, el cine y la ilustración comparten rasgos teóricos metodológicos y circulan entre ellas una enorme variedad de conceptos que lo mismo se aplican para una que para otras artes. Es importante señalar, en este sentido, lo que afirma Antonio Monegal en la Introducción a Literatura y Pintura (2000) titulada "Diálogo y comparación entre las artes" cuando dice:

Toda la teoría de las «artes hermanas» (otra metáfora) se basa en un paralelo entre las capacidades respectivas de la literatura y la pintura para representar el mundo, no en una identificación entre los recursos identificados. Cada una de ellas representa de un modo distinto y, en consecuencia, la afirmación de la diferencia entre las artes es fácil de justificar como una actividad prudente y sensata, mientras que postular la semejanza da pie a confusiones y exageraciones. (Monegal, 2000, pág. 11)

La relación entre la literatura y la pintura es un tema que ha trabajado, entre otros, Mario Pratz en Mnemosyne: el paralelismo entre la literatura y las artes visuales (1970). En este texto Pratz, afirma que, al pensar la imbricación entre el fenómeno literario y la expresión visual es posible observar una relación que, según él, nos acerca a la inspiración (pág. 9). Nosotros consideramos que este acercamiento al fenómeno de la inspiración artística deviene de las formas de expresión que se utilizan en cada discurso y que nos permiten elaborar, a partir de un contenido simbólico, la asociación con nuevos horizontes de interpretación. De esta relación es posible observar aplicaciones visuales de expresiones nacidas en la literatura. Lo anterior nos permite preguntarnos ¿Qué produce la poesía que al encuentro con ella el hombre se siente en un viaje sin retorno hacia sí mismo? Sin lugar a dudas, podemos decir que la poesía produce imágenes y que estás imágenes están asociadas con sensaciones, estados de ánimo o conductas existenciales. La creación y el desarrollo de estas conductas nos permiten pensar que es posible desarrollar una propuesta inter-artística en la que, tal como lo defiende Monegal, veamos esta relación como "la imbricación entre palabra e imagen, y abordar las dimensiones institucionales de la delimitación en el marco general de la cultura, tanto delas artes como de los discursos disciplinares sobre las mismas"(Monegal, 2000, págs. 17-18). 
En "La analogía entre la Pintura y la literatura", Wendy Steiner establece que la relación entre literatura y pintura es un caso privilegiado porque en su opinión, dicha imbricación, trata de "una metáfora sobre el parecido en sí y de manera todavía más significativa, sobre el parecido entre la realidad y los sistemas que el hombre ha desarrollado para representarla". (2000, págs. 26-27). Steiner determina a esta relación «espejo de realidad». En este sentido, la aparición de las ilustraciones que sobre El ingenioso Hidalgo Don Quijote de la Mancha(1605), La divina comedia(1472) o La Biblia que desarrollaraGustave Doré (182-1883) resultan, al menos significativas, y nos permiten indicar que, si tal como lo defiende Steiner para el caso del arte barroco, la función del arte es "evocar imágenes" (Steiner, 2000, pág. 38), la ilustración es un modo de fijación de dichas evocaciones.

En torno a esta relación entre texto poético e ilustración creemos que es posible decir, tal como lo sostiene Henry Markiewicz en «Ut picturapoesis»: Historia del Topos y del problema (2000) que:

[...] la obra poética se desarrolla en el tiempo, mientras que la imagen perdura; el poema puede «provocar la imaginación de todo lo que viene al pensamiento», mientras que la imagen sólo representa una efigie humana; el poema puede representar también lo inimaginable, o sea, un pensamiento, mientras que un cuadro solo lo logra mediante un símbolo; el poema está realizado con un material que no resiste muchoy que deja más libertad que un cuadro; también excita e ilusiona al receptor, más fácilmente, mediante efectos acústicos y no como un cuadro, que sólo se dirige al sentido de la vista exigiendo una intensaimpresión visual(pág. 53).

De este modo,Markiewicz justifica, en el mismo sentido que Setiner y Monegal, la imbricación entre la literatura y la pintura.

Ahora bien, aunque podemos decir que hay una suerte de acercamiento entre las artes es necesario admitir, como lo hace Jean Laude en "Sobre el análisis de poemas y cuadros" (2000) que: "absolutamente todo diferencia a un texto literario de un cuadro o un dibujo: su concepción, su método de producción, sus modos de apreciación, su identidad como objeto irreductible a cualquier otro objeto, y su funcionamiento autónomo"(pág. 89), y sin embargo, debemos aceptar que las prácticas artísticas están ligadas con un imaginario cultural que nos permite ver cierta especie de travesía cultural operada desde la recepción de una obra literaria y su posterior adaptación la imagen.

Lo anterior nos permite pensarque, tal como lo dice Jean Laude:“enlazar la poesía con la pintura implica en especial efectuar una elección entre los elementos a considerar. Hic jacetlepus".(Laude, 2000, pág. 105).

A partir de estas reflexiones queremos postular que al ser expresiones resultantes de la representación, "palabra e imagen -según lo sostiene ÁaronKibédi-, pueden aparecer simultánea o consecutivamente"(2000, pág. 112). Sabemos que cuando el texto precede a la imagen hablamos de una ilustración, si por el contrario, la imagen precede al texto estamos frente a lo que se conoce como una écfrasis.

Para el trabajo que nos ocupa, es necesario advertir, que conduciremos la obra del poeta sinaloense Gilberto Owen El libro de Ruth a un soporte digital de orden visual que es la Ilustración digital. Es necesario advertir que nos interesa desarrollar dichas ilustraciones del poema de Gilberto Owen utilizando algunos de los presupuestos estéticos de Gustave Doré y, debido a ello, abordamos a continuación algunos de los aspectos más significativos de su obra.

\section{Gustave Doré: Literatura y expresión visual.}

La obra de Gustave Doré es, sin lugar a dudas, una de las expresiones más significativas de la ilustración y la xilografía. En este apartado, nos interesa indagar algunos de los aspectos expresivos de su trabajo e identificar algunos de sus rasgos estilísticos para desembocar dichos hallazgos en la creación de una serie de ilustraciones en torno al poema de Gilberto Owen, El libro de Ruth (1946).

En "Aspectos creativos de la obra de Gustave Doré" (2004), Juan Rodrigo Lobato Castaño alude a la obra del ilustrador, pintor y escultor nacido en Estrasburgo como una expresión cargada de "interés por la objetividad representativa y [...] fidelidad arqueológica" (2004, pág. 8). Al respecto, Pedro Payan Sotomayor considera que Doré "pudo captar sobre el terreno mismo la variedad española" (1996, pág. 656). Las visiones de Lobato y Payán nos permiten confirmar que la Ilustración de Doré alcanza niveles de representación que rozan la perfección y constituyen, en sí mismos, un modo de acceder a la realidad de los paisajes y las escenas dramáticas que su obra representa y se observan en las ilustraciones torno a la obra de Miguel de Cervantes Saavedra, El ingenioso hidalgo Don quijote de la Mancha. 
El impacto del trabajo de Doré le ha valido un espacio significativo en la historia de las artes visuales porque ha dotado a la Ilustración de una dimensión estética que, según lo hace notar Lobato Castaño, amplió el impacto de técnicas como la litografía y la xilografía de finales del siglo XVIII y las llevó a ser la expresión de un arte vivificante que pronto se colocó frente a sus parientes visuales como un arte autónomo y de un amplio contenido estético.

El propio Lobato Castaño considera que uno de los aspectos más importantes del trabajo de un ilustrador consiste en "proporcionar una imagen adecuada y creíble a la escena ilustrada, captando la esencia de la historia, además de no perder el rasgo semántico que lo vincula al texto"(pág. 9). Esto permite a Doré mantener al espectador frente al referente literario tal como lo muestran sus trabajos sobre el Quijote, La Divina comedia, La Biblia o diversos aspectos de la obra de Edgar Allan Poe. Pedro Payán Sotomayor afirma que debemos a Doré la memoria visual de la obra cervantina. Nosotros consideramos que el imaginario del personaje quijotesco está asociado, necesariamente, con la obra del francés y, esto sucede, casi inevitablemente, de la misma manera respecto de las escenas bíblicas.

En la "Presentación" al catálogo de la exposición: Doré y las Fábulas de La Fontaine en la Colección UC de Arte Gráfico, realizada entre el 22 de marzo y el 22 junio de 2013 en Santander y publicado por la Universidad de Cantabria, España, José Carlos Gómez Sal afirma que:

[...] Doré consiguió mayor repercusión por la fama y reconocimiento que ya disponía el creador galo en la segunda mitad del siglo XIX. La perspectiva decimonónica que otorgó a las ilustraciones de los textos de La Fontaine complementaba la intención didáctica de cada una de las fábulas.(pág. 5).

La opinión de Gómez Sal, nos hacepensar que la técnica de Doré revela un dominio exquisito de los soportes sobre los que desarrolla su trabajo. Además, las ilustraciones que pueden consultarse en el catálogo muestran también la unión, no sólo de dos mentalidades artísticas, sino de dos artes y confirman lo que en el apartado anterior dijimos sobre la relación entre las artes visuales y la literatura según lo cual: todo lo que puede decirse, puede pintarse.

En el mismo catálogo resalta el "Estudio" de Borja Rodríguez Gutiérrez titulado "Dos personalidades artísticas. Dos obras complementarias" que, además de acercarnos a la obra de La Fontaine y Doré, nos muestra algunos de los rasgos estilísticos del ilustrador y confirma nuestra opinión sobre la maestría de su expresión.

Según Borja Rodríguez, para el caso de las ilustraciones de las fábulas de La Fontaine, el ilustrador se enfrentaba a "un desafío en el que [...] tenía que demostrar su categoría de artista. Su imaginación, su entusiasmo, el fervoremocional y de sentimiento, su espontaneidad y su originalidad"(Rodríguez Gutiérrez, 2013, págs. 13-14). En opinión de Borja Rodríguez, la fábulas fontaineanas son exquisitos cuadros de costumbres en los que la fantasía se aleja del sentido mimético de la representación con que se ha caracterizado a Doré. El reto para el ilustrador era rescatar el carácter adoctrinador de la moral de los estudiantes franceses que leían a La Fontaine y, debido a ello, Doré:

[...] No pretendió representar las escenas de pedagogía social de La Fontaine, sino crear mundos de Doré a partir de los textos de La Fontaine. Mundos enormes, salvajes, ominosos, crepusculares y mágicos a partir de las sencillas historias sociales y ciudadanas del bienhumorado y ligeramente escéptico "amigo de todas las cosas.(pág. 15)

Para confirmar la idea sobre porqué a Doré no le interesa la representación moral o social de la fábula de La Fontaine, Rodríguez Gutiérrez nos hace notar que, en veintiuna de las láminas que componen el catálogo de Doré, el protagonista de la imagen no es un hombre o un animal sino el bosque . Un bosque -afirma Rodríguez Guitierrez:

[...]plenamente romántico: espeso, oscuro, intrincado, misterioso. Un bosque de árboles enormes y enormes dimensiones donde los seres humanos aparecen empequeñecidos, donde los animales protagonistas de la historia apenas se ven. El mismo bosque o muy parecido al que Doré dibujará para ilustrar las aventuras de Arturo, Ginebra, Galahad y Merlín en los Idilios del Rey de Tennyson, que aparecería en Londres un año después de la de estas Fábulas, en 1869. Es decir un bosque romántico que nada tenía que ver con el mundo de La Fontaine(pág. 15).

Nosotros creemos que la intención de Doré es representar la majestuosidad del espacio y, debido a ello, se centra en los espacio exteriores ya que en ellos la posibilidad de vincular el encuentro de sus personajes con lo sublime es mayor. 
En este sentido, Rodríguez Gutiérrez, alude en su intervención, a la aparición de los primeros planos y la iluminación que le permiten resaltar el hecho de que los personajes no siempre ocupan un espacio mayor dentro de la ilustración.

El mismo Borja Rodríguez considera que un artista que ilustra un texto de otro artista debe evidenciar su interpretación sobre la obra ilustrada o no podemos hablar de lo que él llama «recepción activa». Gracias a esta consideración, Doré pudo mostrar - afirma Rodríguez- :"su personalidad y su modo de ver las cosas: de las Fábulas del elegante cortesano que fue La Fontaine [y] creó una serie de bellas estampas, teñidas de su subjetividad" (pág. 18). El artista ha de fascinar por la fuerza de su expresión y, sin lugar a dudas, Doré expresa en su representación fontaineana: "Un mundo romántico que fascina por su riqueza de imaginación, por su desmesura, por su originalidad y por su fuerza. Las características que han hecho de Doré un artista incomparable, único e irrepetible"(pág. 18).

En el mismo catálogo que hemos venido refiriendo, Juan Martínez Moro , Joaquín Cano Quintana y Joaquín Martínez Cano, resaltan en la expresión estética de Doré algunas categorías relevantes para nuestro trabajo: el escorzo, la secuencia de planos y la iluminación. El escorzo es, según nuestros autores "el dibujo de los cuerpos humanos o animales colocados en una posición de perspectiva muy forzada”.(Moro Martínez, 2013, pág. 51).

Martínez Moro, Cano Quintana y Martínez Cano señalan que uno de los aspectos más importantes en la obra de Doré es la secuencia de planos. Como sabemos esta estrategia es fundamental para desarrollar el contenido narrativo de las escenas que se representan en cualquier secuencia narrativa. Los autores, aluden en el apartado de material Didáctico del texto Doré y las Fábulas de La Fontaine en la Colección UC de Arte Gráfico, a la abundancia de esta categoría narrativa en el texto de Doré.

La última categoría que queremos rescatar de las observadas por Martínez Moro, Cano Quintana y Martínez Cano es la iluminación. Nuestros autores acentúan el hecho de que "La iluminación es una parte fundamental de cualquier representación visual"(Moro Martínez, 2013, pág. 53). Para quienes desarrollan el material didáctico del catálogo citado anteriormente, la iluminación en la obra de Doré: "consiste en acentuar mucho los contrastes entre luz y oscuridad"(pág. 53), gracias a este manejo del contraste, la estampa nos pone en contacto con "diferentes planteamientos de claroscuro"(pág. 53) y permite atestiguar la sugerencia luminosa de los cuerpos, el paisaje y las escenas interiores.

Nosotros queremos, desarrollar, a partir de estas categorías doreanas, una serie de ilustraciones en torno a la obra de Gilberto Owen, El libro de Ruth. Antes, sin embargo, debemos dilucidar algunos aspectos temáticos que nos permitan explicitar el tratamiento visual que queremos darle nuestro trabajo.

\section{El libro de Ruth de Gilberto Owen.}

La generación de Contemporáneos aparece en la historiografía de la literatura mexicana como un grupo que abordan en su poesía, según la opinión de Blanca estela Domínguez Sosa:

[...] los problemas del subconsciente, penetran en las profundidades del ser, estructuran un discurso poético alrededor del tema de la muerte, el sueño y el deseo. El tono de esta poesía se vuelve íntimo, discreto y reservado; el poeta ya no se exalta medita y se confiesa. (Domínguez Sosa, 2003, pág. 22).

La actitud poética de Contemporáneos que los asocia a la concepción poética de Paul Valery y al surrealismo mientras los nutre de la literatura de André Gide y Jean Cocteau. Esto los aleja de las ideologías surgidas en México entre los años veinte y treinta en los que el país pretende desarrollar una tendencia altamente nacionalista en el arte y los hacer ser, según lo nota la propia Domínguez Sosa: "una voz potente, original y crítica, en un mundo dominado por las fuerzas sociales, políticas, culturales, ideológicas surgidas de la Revolución Mexicana"(2003, pág. 13).

En Contemporáneos el deseo aparece como potencia única a partir de la cual puede actualizarse el arte, lo sagrado, lo erótico. En ellos: "el juego de la vida es eso -el deseo es el movimiento de algo que va hacia lo otro como hacía lo que falta de sí mismo. Y eso quiere decir que lo otro (el objeto de deseo) está presenta en quien desea, y lo está en una forma de ausencia”(Domínguez Sosa, pág. 9). Esta ausencia que se vuelve búsqueda hace que la búsqueda se vuelva permanente. En esta ruta, la de la búsqueda permanente de la fijación del deseo aparece la poesía de Gilberto Owen.

Owen es consciente de que el deseo aparece en la vida del hombre como una barrera que le impide llegar a sí mismo. Por eso, es en el deseo donde el poeta encuentra su propio destino, luchar por desarticular ese dique es lo que somete al poeta a la poesía.

154 
Perseo Vencido, Sindbad el varado representan, probablemente mejor que ninguna otra de las obras del sinaloense, este aspecto del viaje inmóvil que solo puede tener como destino al viajero y la poesía. Ahí, en la poesía, Owen se desdobla para ser, a un tiempo, él mismo, y los personajes que dan sentido a sus obras: Perseo, Sindbad y Bozz.

Ese itinerario por medio del cual, a decir de George Bataille, el hombre "escapa del mundo del discurso, es decir, del mundo natural (de los objetos);"(2008, pág. 24), puede aplicarse, sin lugar a dudas, a la poesía del sinaloense ya que con la poesía Owen, tal y como lo dice Bataille para el caso del erotismo: "entró en una suerte de tumba donde la infinidad de los posibles nace de la muerte del mundo lógico" (Bataille, 2008, pág. 24). Por medio del lenguaje poético, del delirio, el autor de Sindbad el varado accede a un universo que se basta a sí mismo para resignificar aquellos relatos que toma como seminales en Perseo Vencido.

El libro de Ruth(1990)es el último poema de Perseo Vencido. En este poema, el sinaloense juega con el relato bíblico para re-simbolizarlo. En el relato bíblico, Ruth, la moabita, es el instrumento que sirve a Bozz para dar la descendencia de la cual nacerá el Rey David. Es significativo que el relato bíblico termine precisamente con la genealogía de David (Rt, 4, 18-ss). Sin embargo, en Owen, lejos de valorarse las virtudes de Ruth, compañera in extremis de Noemi su suegra, resuena la invitación de Bozz:

$$
\begin{gathered}
\text { "tiéndete bajo el pino más erecto, } \\
\text { una brizna de hierba entre los dientes, } \\
\text { no te muevas. Así, fuera del tiempo" (pág. 93). }
\end{gathered}
$$

Junto a otras, la expresión «Pino erecto», en tanto metáfora de la imagen, nos permite articular la posibilidad de una lectura erótica del poema de Owen y vincularlo con algunas de las propuestas que Georges Bataille ofrece respecto del erotismo y el deseo para trasladarlos a una expresión visual digital del poema de Owen respecto de las propuestas estéticas que anteriormente identificamos en la obra de Gustave Doré: el escorzo, la iluminación y la secuencia de planos.

\section{Erotismo y deseo en El libro de Ruth de Gilberto Owen.}

El hombre es un ser proyectante, su voluntad, una voluntad tendente que tiene en el deseo su definición más acertada. El hombre debe romper con aquello que lo detiene para afirmar su voluntad ya que éste lo pone siempre ante el fracaso de sí mismo.

Uno de los aspectos donde se manifiesta de forma más significativa el deseo es el ámbito sexual. Más allá de las acuñaciones instintivas o inmorales que le han sido impuestas al deseo sexual por la religión y la moral debemos insistir que éste es algo propio del hombre, es más, sin él no es posible afirmar su humanidad.

El erotismo, al igual que el deseo, manifiesta una condición definitoria del sujeto. En El erotismo (1957), Georges Bataille define este concepto como "la aprobación de la vida hasta en la muerte"(pág. 15). Entendemos que, para el francés, la aprobación que en el sentido de afirmación de la vida tiene el ámbito sexual, es el rasgo definitorio del hombre y debido a ello la finalidad del goce erótico no debe ser eludida.

Erotismo y deseo articulan una diada altamente significativa en El libro de Ruth de Gilberto Owen. Son, en nuestra opinión, una simbiosis productiva que representa la incorporación de un ser en otro. Marca que articula al ser en tanto Otro al tiempo que se vuelve la representación de sí mismo. Si como afirma Bataille: "en el erotismo, yo me pierdo". (pág. 341), es porque la experiencia erótica es una experiencia de fundición del ser y, en ella, uno se afirma en la flagrante pérdida voluntaria de la que nadie puede dudar. En lo erótico, el sujeto, tal y como lo manifiestan las experiencias de los místicos, se pierde a sí mismo y,por eso, el lenguaje es incapaz de manifestar en su totalidad esa experiencia.

En este punto, resulta por lo menos interesante, recordar que las experiencias místicas de Santa Teresa de Ávila fueron asociadas con patologías psicológicas o posesiones demoniacas por sus confesores o, que el Cántico Espiritual de San Juan de la Cruz que busca manifestar la ascensión del alma a Dios esté cargado de manifestaciones eróticas en el mismo sentido que el Cantar de los cantares del Rey Salomón. Sea cual sea la razón de dichas manifestaciones,éstas parecen evidenciar que el erotismo y la experiencia de Dios tienen el mismo lenguaje: la fascinación. Bataille considera que esa fascinación se da en tres niveles en el hecho erótico: el de los cuerpos, el de los corazones y el erotismo sagrado. Según el francés, el erotismo de los corazones manifiestaque "la pasión de los amantes se prolonga, en el dominio de la simpatía moral, la fusión mutua de los cuerpos"(pág. 24). 
En el erotismo sagrado: "nada desplaza al sujeto(pág. 28)" porque éste siempre está "a la espera de un ser dado y de unas circunstancias favorables"(pág. 28), es decir, busca una relación absoluta con el Absoluto. En torno al erotismo de los cuerpos, Georges Bataille afirma que el erotismo no está necesariamente vinculadoal placer sino a una forma de ascensión a la fundición con el otro a la que es posible acceder desde el cuerpo.

En "El erotismo o el cuestionamiento del ser" Bataille afirma: "el erotismo es uno de los aspectos de la vida interior del hombre"(2008, pág. 338) y, en tanto experiencia interior, nos conduce al olvido del ser. Debemos comprender que para Bataille, en la relación erótica, el otro no es un objeto exterior sino que su presencia responde a aquello que él denomina la interioridad del deseo y que la literatura asociada al erotismo simplemente intenta describirdicha experiencia:

[...] Si la literatura se encarga de describir expresamente la voluptuosidad, escoge objetos y escenas que tienen la capacidad de determinar la conducta sexual del lector, o al menos de esbozarla. Pero al leer, queda claro que esos objetos se han vuelto de algún modo angustiantes o risibles para nosotros y que esto mantiene de manera completamente extraña al "lenguaje de interés inmediato" dentro de los límites de la decadencia y la desgracia(Bataille, La felicidad, el erotismo y la literatura Ensayos 1944-1961, 2008, pág. 104).

En este sentido El libro de Ruth de Gilberto Owen, describe ese deseo que la voluptuosidad genera, lo desarrolla, lo lleva a alcanzar su expresión más significativa: la de la unión de los amantes. Podemos decir, como lo cree Tomás Segovia que para Owen: "seducir es entregarse a la entrega del otro y buscar su entrega a la nuestra"(Segovia, 2001, pág. 99).

En El libro de Ruth, Booz no deja de manifestar el deseo que tiene de la moabita cuya principal función en el relato bíblico es ser la mujer que permitirá que el linaje del cual surgirá el rey David se mantenga vivo. La resignificación que elabora Owen aparece precisamente cuando, lejos de evocar la virtud y empatía de la moabita hacia su suegra, el poeta sugiere la búsqueda permanente del cuerpo de Ruth por Booz.Owen vitaliza el relato de Ruth estableciendo una re-significación. En el poema de Owen, Bozz no rescata a Ruth es rescatado por ella cuando éste la posee. Sin embargo, para poseerla tiene que desearla y, en ese sentido, sólo la poesía puede describir dicha experiencia. Esa posesión comienza, en el libro de El libro de Ruth, por la impaciencia que experimenta Booz cuando se abre al deseo de la experiencia erótica.

El deseo que Booz manifiesta por Ruth, y que en cierto sentido lo mantiene vivo, se hace más evidente cuando, en "Booz ve dormir a Ruth", con oraciones desiderativas la voz poética afirma:

Quién habitará tu veraz incendio

Rodeado de azucenas por doquiera,

Quién entrara a tus puertos cerrados

Azules y redondos como ojos azules

Que aprisionaron el sol del día

Para irse a soñar a tu serena plaza pueblerina (pág. 93).

Este deseo se encuentra antecedido por dos partes del poema en las que se evidencia la impaciencia que experimenta el hombre ante la imposibilidad de satisfacer el objeto de su deseo. En "Booz se impacienta", la voz, consciente de que un nuevo día ha comenzado y la media noche culmina con la esperanza de acceder al cuerpo que sacie sus impulsos afirma:

Las mujeres apagan las lámparas del mundo entero,

el cielo sus estrellas. Yo mi espera" (pág. 90).

El deseo seguirá permanentemente y la alusión a la masturbación, en tanto placebo de esa satisfacción que rompe el dique producido por la necesidad que deviene deseo del acto erótico, aparece un par de versos más tarde:

Dedos que no son tuyos han bajado mis párpados.

Ya no vienes, no llegas

Más allá de las doce no se puede ver nada”. (pág. 90).

El deseo se exaspera cuando al final de esa primera parte del poema vemos como con una oración imperativa Booz haciendo más abigarrada su espera grita:

Deja la luz sin sexo en que te ahogas

Ángel mientras mi lecho no te erija mujer...

Deja la arcilla informe que habitas y que eres 
En tanto que mis dedos no modelen tu estatua

Sal del bosque de horas inmortales en que te pierdes" (pág. 91).

Hasta aquí, no parece haber una destinaria objetiva de esa espera, todas las mujeres son una. Sin embargo, ese deseo se personifica en Ruth unos versos más adelante y alcanza su absoluta objetivación en la segunda parte del poema: "Booz encuentra a Ruth":

De mi saldrás exagüe y destinada a sueño como las

Mariposas que capturan los dedos crueles de los niños;

De mi saldrás seca y estéril como las maldiciones escondidas

En los versos de amor que nadie escucha. (pág. 92).

El poema va tomando fuerza conforme el desarrollo del mismo alude a lo que Georges Bataille afirma del erotismo sagrado cuando supone que éste se caracteriza por una fundición entre los amantes en la cual, uno se encuentra en otro. Dicho ascenso hacia la fundición con Ruth es experimentado por Boozhacia la tercera parte del poema, "Booz ve dormir a Ruth", en ella, la voz refiere una experiencia que si bien no es enteramente física involucra la percepción, primero la mirada de Boooz se pierde en

parasaber por qué tu seno izquierdo

se levanta más que el otro cuando aspiras;

para saber por qué tu vientre liso

tiembla cuando lo tocan mis pupilas (pág. 94).

Posteriormente, la alusión a los sabores en los cuales reconoce a Ruth,

Saben aún tus pies, cuando los beso,

al vino que pisaste en los lagares (pág. 94).

Esta experiencia sensible, signo inequívoco del deseo que produce en Booz el cuerpo de Ruth y de las sensaciones eróticas que le genera, nos conducen a la última parte del poema, la de la experiencia de fundición donde erotismo y muerte se funden como si de una misma experiencia se tratara. En "Celos y muerte de Booz" el poema comienza diciendo: "Y sólo sé que no soy yo"(pág. 94), el verso sugiere esta experiencia de absorción de un amante en otro, la misma experiencia que hace decir a Bataille: "en el erotismo, yo me pierdo"(pág. 341)y supone un olvido de sí en el cuerpo del otro.

Ya me voy con mi muerte de música a otra parte

Ya no me vivo en ti.

Mi noche es alta y mía (pág. 95)

Lo anterior evidencia, desde nuestro punto de vista, el perdimiento del ser por parte de Booz, condición sine qua non el erotismo sagrado no se logra.

En el poema de Gilberto Owen, Booz experimenta "el deseo, el encuentro, la declaración de amor, la contemplación postcoital y la separación- con más sabor a vehemencia de amante furtivo que del esposo recompensado que devendrá, como en la Biblia, en bisabuelo de David”. La experiencia nos sugiere un paso por los tres estadios eróticos definidos por Georges Bataille y nos han permitido establecerlos como un itinerario del poema hacia la fundición de un ser y otro supuesta por el erotismo sagrado descrito por el filósofo francés.

La grandilocuencia de la experiencia erótica tiene para nosotros la misma dificultad en manifestarse, por medio del lenguaje, que la experiencia de los místicos ya que es una experiencia de transgresión que sólo logra consumarse cuando el deseo de transgredir la experiencia misma genera una "experiencia interior del erotismo [que] le exige a quien la realiza una sensibilidad equivalente tanto ante la angustia que funda la prohibición como ante el deseo que lleva a infringirla(Bataille, pág. 349)". En el erotismo, angustia y deseo se configuran como una sola cosa, por ello el hombre, ante la experiencia erótica, se encuentra como ante la muerte. Es por ello que Booz no puede sino afirmar: "Ya no me vivo en ti"(pág. 95)

La separación postcoital significa la muerte de Booz o, al menos, la re-apertura del deseo y la necesidad de la seducción que siempre suponen un encuentro con la Diosa Fortuna.

\section{Ilustraciones}

Luego de desarrollar el análisis de algunos de los aspectos temáticos, conceptuales y creativos de nuestro trabajoes momento de describir el desarrollo de nuestra propuesta artística. 
En ésta, hemos desarrollado cinco ilustraciones que obedecen a una interpretación visual de la obra de Gilberto Owen El libro de Ruth a partir de lascaracterísticas que hemos mencionado de la propuesta estética de Gustave Doré.

Hemos hecho notar tres características de la obra de Gustave Doré que nos interesan en la medida que nos permitenanalizar su expresión plástica. Puesto que lo que nos importa es desarrollar una manifestación visual de la mano del poema Gilberto Owen, El libro de Ruth resulta importantísimo para nosotros vincular el escorzo, la secuencia de planos y la iluminación que descubrimos en Doré en la realización de nuestras ilustraciones. A continuación identificaremos algunos aspectos relativos a cada categoría y los implicaremos en las decisiones creativas desde las que se opera nuestras ilustraciones.

\section{El escorzo.}

Tal como lo explicamos en el apartado sobre la poética de Gustave Doré, de la mano de Moro Martínez, Cano Quintana yMartínez Cano, el escorzo es:"el dibujo de los cuerpos humanos o animales colocados en una posición de perspectiva muy forzada".(pág. 51). Como se muestra en la siguiente figura:

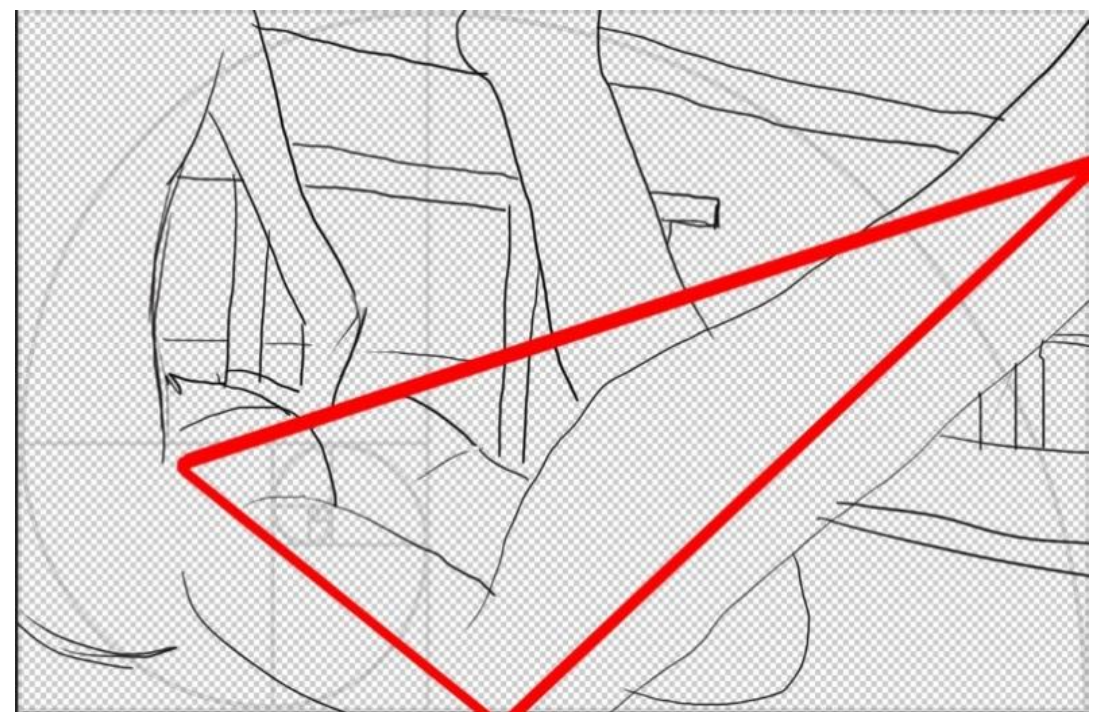

Figura 1. Boceto: "Por la carne también se llega al cielo".

Nosotros hemos desarrollado el escorzo en este boceto para establecer el sentido que las líneas toman al momento de desarrollar nuestra interpretación visual del poema. De este modo, podemos recorrer visualmente el espacio marcado en el triángulo rojo sobre el cuerpo femenino desde las nalgas hasta el tobillo. Si observamos con atención, en el boceto, la perspectiva se percibe forzada y genera una sensación estirada. La idea es rescatar la expresión doreana que hemos descrito anteriormente según la cual, el escorzo, permite a Doré indagar en la expresión de la posición de sus personajes en la escena e incentivar el desarrollo narrativo de sus grabados.

Si se observan algunos detalles del boceto, la sección aurea, desde la que señalamos el escorzo, nos permite identificar el espacio donde la escena se desarrolla. Junto a esa identificación es posible notar que hay tres planos. El primer plano se ubica en el punto de interés; el sexo de Ruth, nos da la posibilidad de establecer la condición retórica de la imagen. El sexo es, aún si en el ámbito moral no es así, un modo de llegar a Dios. La alusión al erotismo se hace evidente en la imagen por su pertenencia al texto al que ésta ilustra. En términos visuales el escorzo nos ofrece un sentido narrativo en el que el espectador se ancla. Es decir, en Doré, el escorzo ofrece un punto de origen a la lectura. El segundo plano está marcado por la locación y el tercer plano por el fondo que supone la ciudad fuera del espacio donde los amantes se encuentran.

En la siguiente imagen, podemos observar, nuevamente, la manera en que el escorzo posibilita el desarrollo de las escenas desde una perspectiva que se observa con frecuencia ambigua y supone una indeterminación respecto de la sintaxis de la imagen que, aunque fijada, es problemática. La figura que a continuación se presenta identifica cuatro de nuestras ilustraciones y en ella se identifica en rojo el escorzo. 


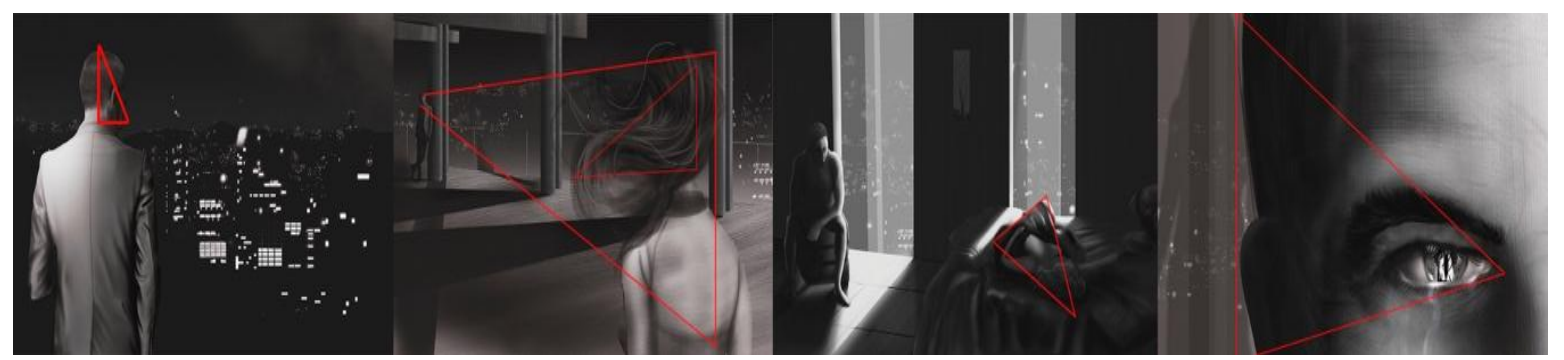

Figura 2. Boceto. Identificación del Escorzo.

\section{La secuencia de planos}

Otro elemento importante de la expresión doreana que hemos querido resaltar es "La secuencia de planos". En torno a este aspecto de la creación artística del ilustrador francés, los autores de Doré y las "Fábulas" de La Fontaineen la Colección UC de Arte Gráfico consideran este recurso como: "esencial para toda narración visual" (pág. 52). Dicha secuencia permiteque planifiquemos el seguimiento de los personajes o escenarios y podamos situar la continuidad narrativa. Por medio de la secuencia de planos logramos un seguimiento óptimo de la narración visual. Esto significa que al identificar los planos en la escena, la perspectiva marcada por el escorzo se optimice.

En esta serie de ilustraciones se ve un seguimiento de escenarios y personajes situados en un departamento. En la escena, podemos los personajes interactuan con barandales, cristales y, en el fondo, la Ciudad de México.

En los bocetos que se presentan a continuación y corresponden, en nuestra obra, a los versos de Owen que afirman: «Así iré mutilándome hasta las doce de la noche, más si llegaras un minuto antes en él todas mis dichas vivirías de nuevo» y «Tras un viento que mueve los rascacielos más tercos y que [te ciñe para mostrarme cómo fue la cabeza de la Victoria [de Samotracia, y que luego te humilla a recoger espigas desdeñadas», la secuencia de planos se describe con las líneas rojas y blancas.

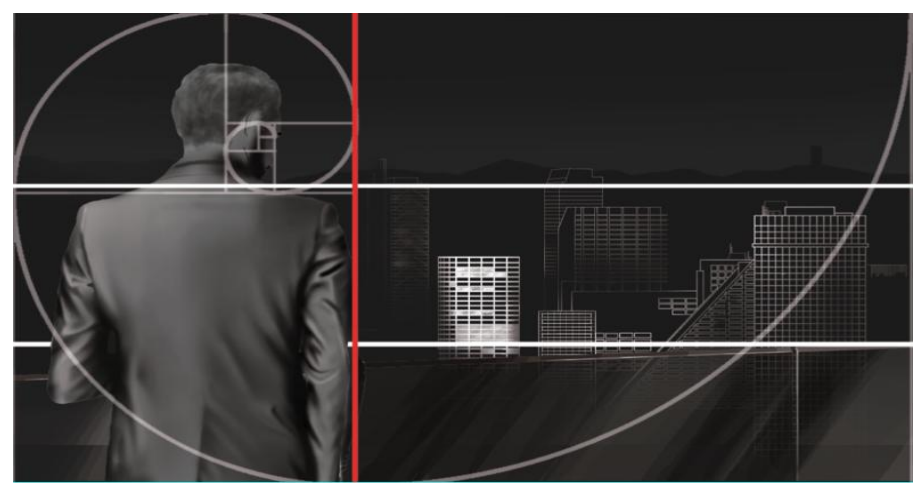

Figura 3. Boceto: «Así iré mutilándome hasta las doce de la noche, más si llegaras un minuto antes en él todas mis dichas vivirías de nuevo».

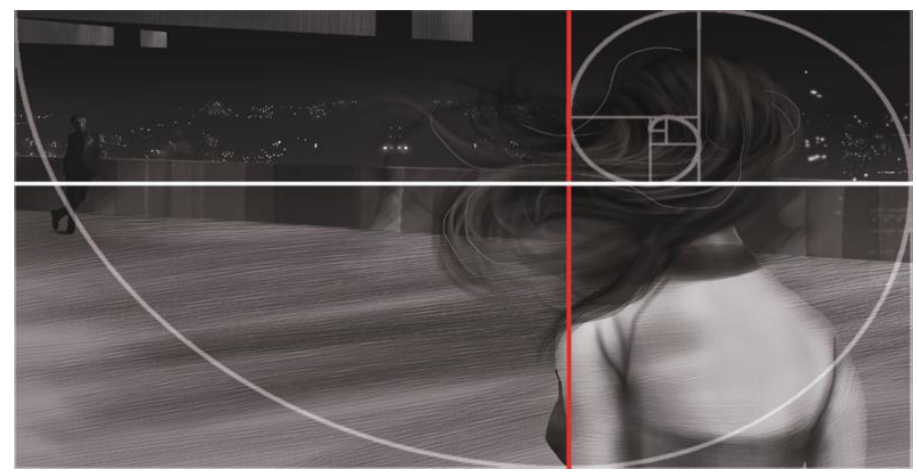

Figura 4. Tras un viento que mueve los rascacielos más tercos y que [te ciñe para mostrarme cómo fue la cabeza de la Victoria [de Samotracia, y que luego te humilla a recoger espigas desdeñadas». 
Si tenemos en cuenta que, la secuencia de planos sirve para marcar una continuidad narrativa que, en nuestros bocetos, se asocia con la continuidad narrativa del poema de Owen, en la figura, se observa a Booz de espalda a la habitación con la mirada perdida en el horizonte de la ciudad y tratando de controlar las ansias que su desesperación por encontrar a Ruth le hace experimentar. Bozz piensa a Ruth, mientras su mirada se pierde en la ciudad. En el nombre del poema se hace referencia a la impaciencia que, por encontrar a Ruth, experimenta Bozz. Esta caracterización lo hace preguntarse si salir a la terraza y ver la inmensidad loconducirá a Ruth e instaura la lógica de un deseo permanente.

Tenemos en un primer plano a Booz, marcado por la línea vertical señalada en rojo. Booz desesperado por encontrar a Ruth. Por otro lado, Ruth ocupa un segundo plano marcado igualmente en rojo que nos permite establecer la secuencia narrativa de Bozz a Ruth.

En la figura, observamos que la secuencia de planos nos ayuda a lograr el seguimiento de la estructura narrativa de la ilustración. En la imagen, en el primer plano, vemos a Ruth cuando Booz la encuentra. La línea blanca nos permite identificar a Booz a lo lejos y con una línea vertical en rojo a Ruth en el primer plano. Lo que la imagen revela es la secuencia narrativa en la que los planos nos permiten observar cómo Booz espera impaciente a Ruth. La secuencia de planos nos da elementos que la primera ilustración nos ofrecía pero, en ésta,Booz queda en segundo plano en la narración visual.En la siguiente figiraobservamos la secuencia de planosde las ilustraciones faltantes.

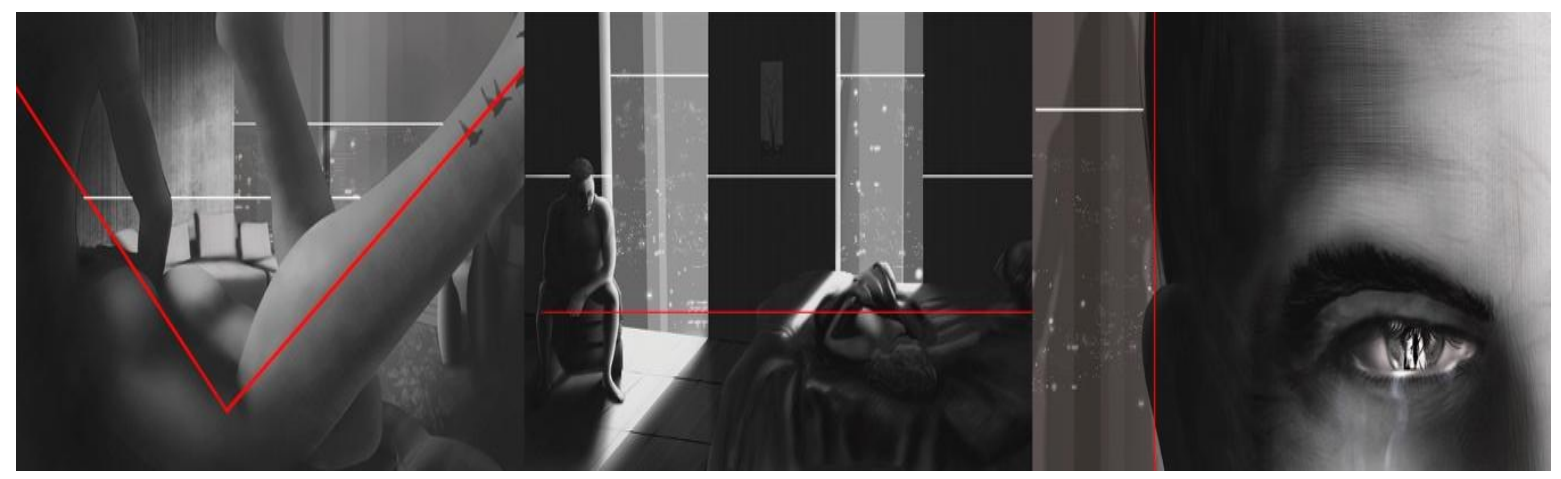

Figura 5. Secuencias de planos de las Ilustraciones.

\section{La Iluminación}

La Iluminación es, "una parte fundamental de cualquier representación visual. Gustave Doré es uno de los grandes maestros en el manejo de este elemento de la expresión visual. Según Moro Martínez: "su técnica consiste en acentuar mucho los contrastes entre luz y oscuridad".(pág. 53). En el cuarto poema del poemario de Owen, El libro de Ruth, titulado, "Booz ve dormir a Ruth". Que describimos a continuación, hemos optado por representar esta característica de la siguiente manera:

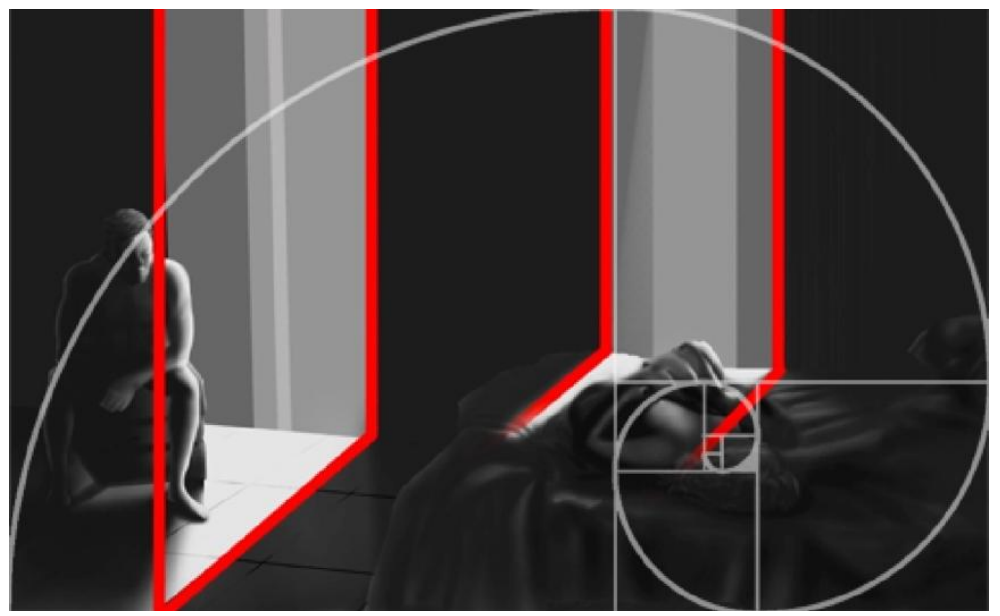

Figura 6. Boceto “[...] yo conocí un río más largo que tus piernas - algunos lo llamaban Vía Láctea- [...]”. 
En la obra de Doré, la iluminación permite dar volumen a la escena de la ilustración y, al mismo tiempo, crea una mayor expresividad. Al acentuar ese claroscuro podemos remarcar los paisajes o los personajes de la escena. Esta característica nos permite ubicar o determinar una aproximación del tiempo-espacio de la que habla Owen en sus poemas mediante la creación de la tridimensionalidad con base en la luz.

El punto de interés ubicado en Ruth que se encuentra dormida y exponiendo su seno izquierdo, permite que, gracias a la iluminación se alcance a ver todo su ser. Ruth es el centro de la condición narrativa, ella es el centro de la Vía Láctea. Su imagen consume todo el pensamiento de Booz. La sección aurea nos lleva de un punto a otro de la Ilustración, de Booz a Ruth.

En la Figura 7 podemos ver el criterio de composición de iluminación de las ilustraciones nos permite observar los elementos de cada una de las escenas descritas en la ilustración con mayor nitidez.

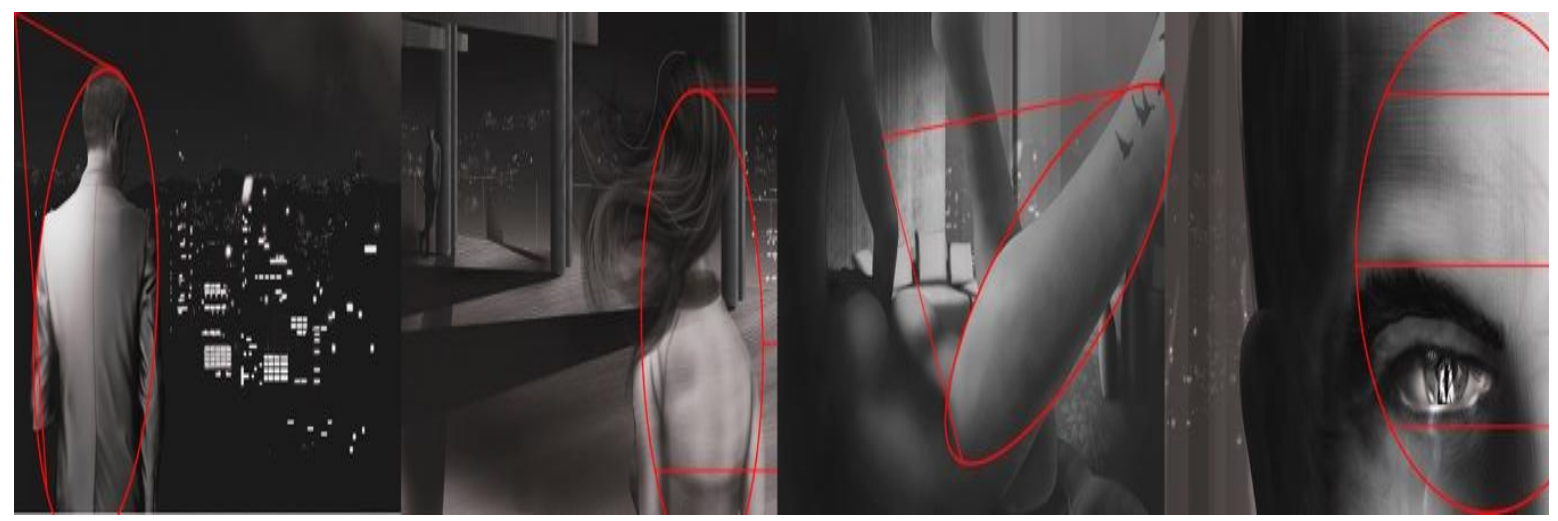

Figura 7.Boceto.
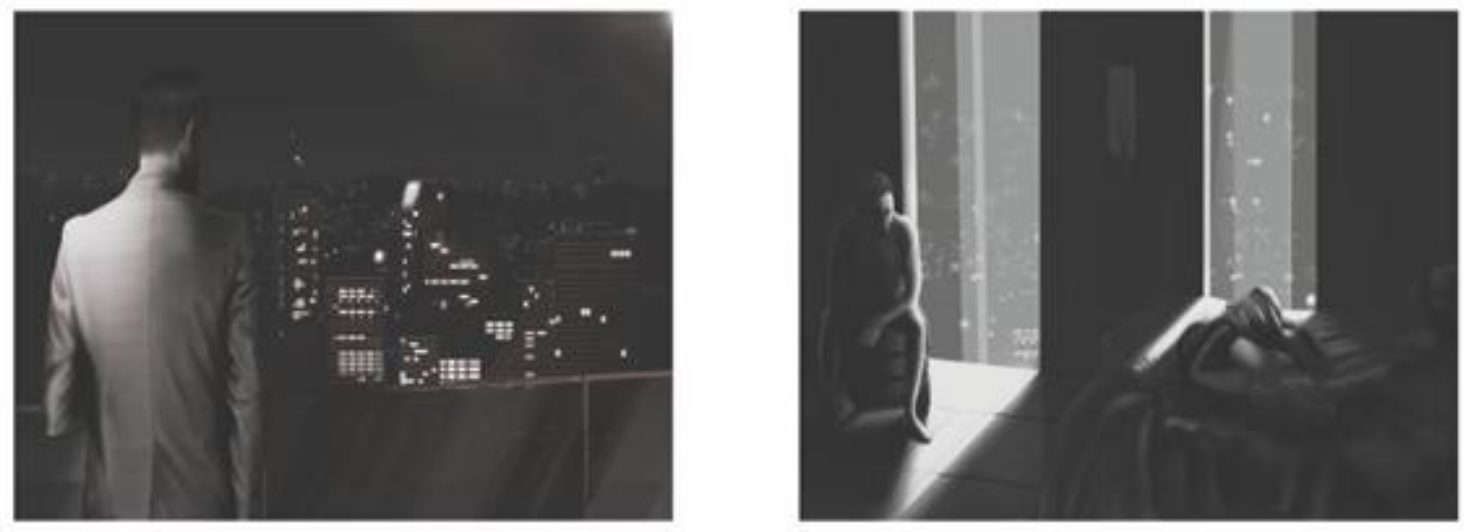

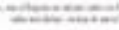
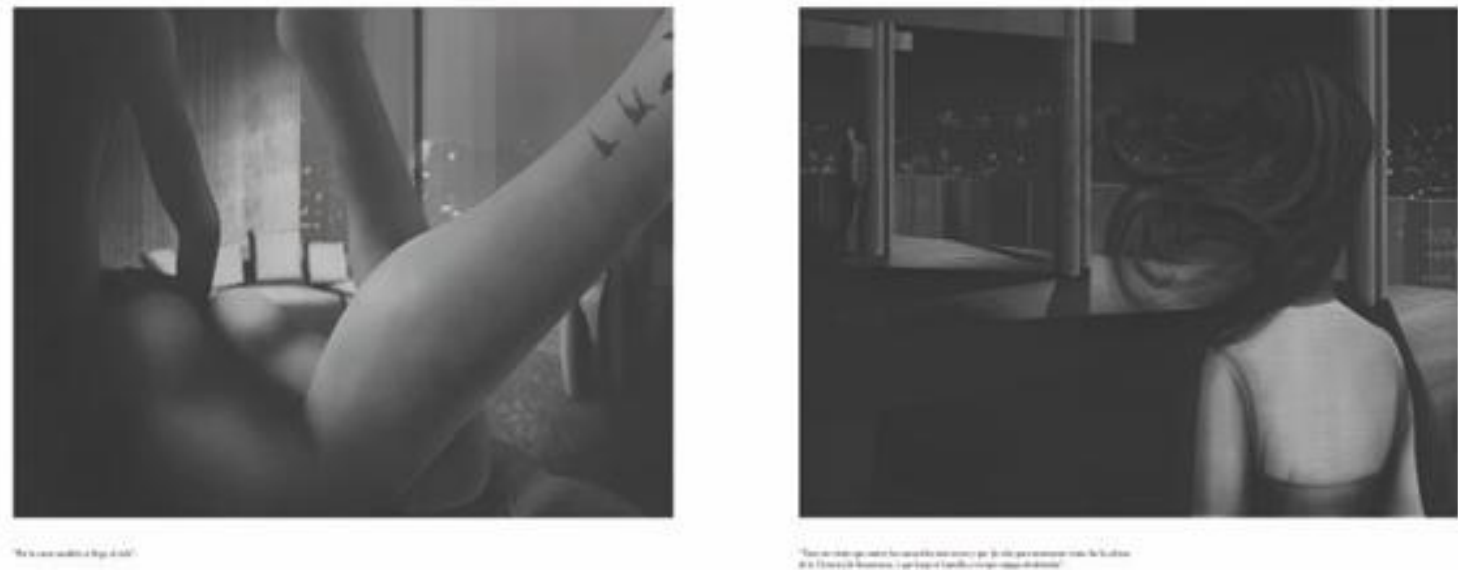


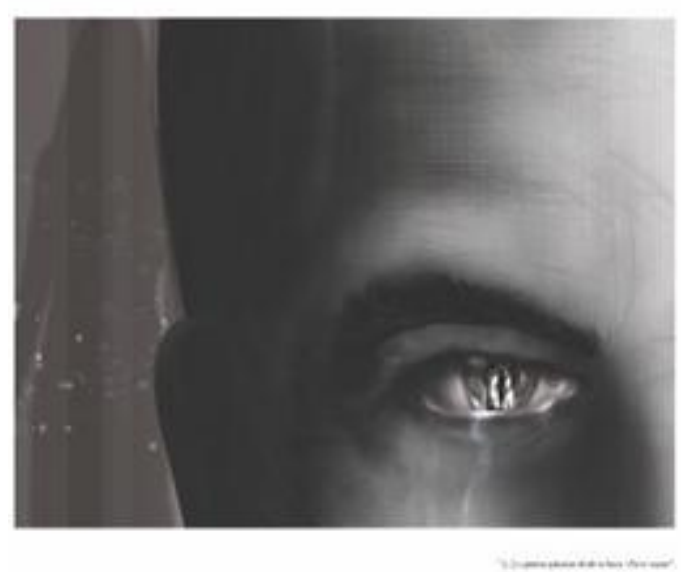

\section{Conclusiones}

A lo largo de este trabajo hemos podido conducir la expresión poética de Gilberto Owen a una manifestación visual. De acuerdo con los autores en los que hemos podido encontrar referentes para esta transformación discursiva, la ilustración nos ha permitido confirmar que aquello que puede decirse, puede pintarse.

En el trabajo la obra poética de Gilberto Owen ha sido analizada a la luz de las propuestas que sobre el erotismo vierte en diversos momentos de su obra, George Bataille. La idea de utilizar ese marco de referencia fue, en síntesis, el establecimiento de un mecanismo de producción visual que nos permitiera resaltar algunos aspectos descritos en el poemario de Owen respecto de la noción del deseo, el extravío del yo por la conducta erótica y la supresión del Yo cuando, en la superación del deseo el sujeto se pierde.

En la configuración de nuestras ilustraciones, las categorías del escorzo, la secuencia de planos y la iluminación descritas en la obra de Gustave Doré han posibilitado que las escenas en las que desarrollamos el contenido narrativo de la serie se vincule con las propuesta bataillinas a partir de la identificación de atmósferas húmedas vinculadas a la temática erótica, la secuencia de planos que describe el movimiento de Bozz a Ruth y la iluminación que se desarrolla básicamente en tonos que se mueven de lo cálido a lo frío.

\section{Referencias}

Bataille, G. (2002). El erotismo. Barccelona: Tus Quest.

Bataille, G. (2008). El erotismo o el cuestionamiento del ser. En G. Bataille, La felicidad, el erotismo y la literatura. Buenos Aires: Adriana Hidalgo.

Bataille, G. (2008). La felicidad, el erotismo y la literatura Ensayos 1944-1961. Buenos Aires: Adriana Hidalgo.

Domínguez Sosa, B. E. (2003). Contemporáneos, obra poética. En B. E. Domínguez Sosa, Contemporáneos, obra poética. Barcelona: DVD ediciones,.

Gómez Sal, J. C. (2013). Presentación. En G. Doré, Gustave Doré y las "Fábulas" de La Fontaine en la Colección UC de Arte Gráfico [exposición: Santander], (págs. 9-18). Santander: Fondo Pedro Casado Ciminano;5.

Kibédi Varga, Á. (2000). Criterios para describir las relaciones entre palabra e imagen". En A. Monegal, Literatura y Pintura. Madird: ARCO/LIBRO.

Laude, J. (2000). Sobre el análisis de poemas y cuadros. En A. M. (1972), Literatura y pintura. Madrid: ARCO/LIBROS.

Lobato Castaño, J. R. (2004). Aspectos creativos de la obra de Gustave Doré. REVISTA ICONO, 1-16.

Markiewicz, H. (2000). «Ut picturapoesis»: Historia del Topos y del problema. En (. Antonio Monegal, Literatura y pintura. Madrid: ARCO/LIBROS.

Monegal, A. (2000). Diálogo y comparación entre las artes. En A. Monegal, Literatura y Pintura (págs. 9-21). Barcelona: ARCO/LIBROS.

Moro Martínez, J. C. (2013). Material Didáctico. En G. Doré, Doré y las "Fábulas" de La Fontaine en la Colección UC de Arte Gráfico : [exposición : (págs. 49-56). Santander: Universidad de Cantabria.

Owen, G. (1990). De la poesía a la prosa en el mismo viaje. México: CONACULTA.

Payán Sotomayor, P. (1996). El Escorial según el Barón Davillier y Gustave Doré”. 649-666.

Pratz, M. (1979). Mnemosyne: el paralelismo entre la literatura y las artes visuales. Madrid: Taurus.

Rodríguez Gutiérrez, B. (2013). Dos personalidades artísticas, dos obras complementarias. En G. Doré, Doré y las "Fábulas" de La Fontaine en la Colección UC de Arte Gráfico : [exposición : (págs. 9-18). Santander: Universidad de Cantabria.

Steiner, W. (2000). La analogía entre la Pintura y la literatura. En A. Monegal, Literatura y pintura. Madrid: ARCO/LIBROS. 